\title{
Grupos educativos na Atenção Básica à Saúde: revisão integrativa de literatura de
}

\section{9 a 2018}

\author{
Educational groups in Primary Care: an integrative literature review from 2009 to 2018 \\ Grupos educativos en Atención Primaria: revisión integradora de la literatura de 2009 a 2018
}

Recebido: 22/07/2021 | Revisado: 29/07/2021 | Aceito: 03/08/2021 | Publicado: 08/08/2021

\author{
Maíra Rossetto \\ ORCID: https://orcid.org/0000-0002-5683-4835 \\ Universidade Federal da Fronteira Sul, Brasil \\ E-mail: maira.rossetto@uffs.edu.br \\ Fabiula Grahl \\ ORCID: https://orcid.org/0000-0001-8466-2092 \\ Prefeitura Municipal de Chapeco, Brasil \\ E-mail: fabiulagrahl@unochapeco.edu.br
}

\begin{abstract}
Resumo
Esta pesquisa objetivou analisar a produção científica brasileira referente ao trabalho em grupos educativos realizados na Atenção Básica entre 2009 e 2018, destacando as potencialidades e dificuldades encontradas pelos profissionais e contribuições dos grupos a partir da implementação do Núcleo Ampliado de Saúde da Família e Atenção Básica. Trata-se de uma Revisão Integrativa de Literatura cuja busca ocorreu na Biblioteca Virtual em Saúde a partir da combinação de nove palavras-chave em oito cruzamentos, resultando em 220 estudos. Dezoito estudos foram selecionados, a maioria utilizou metodologia qualitativa e abordou profissionais de saúde. Quanto ao local de publicação, a região brasileira com maior contribuição foi nordeste, sendo que nas regiões norte e centro-oeste o tema é pouco explorado. O periódico com maior contribuição foi Ciência e Saúde Coletiva. As potencialidades destacadas foram: troca de experiência entre usuários; realização por equipe multiprofissional; vínculo entre profissional e usuário; utilização de espaços da comunidade. Como dificuldades destacam-se: estrutura inadequada; baixa adesão de profissionais e usuários; falta de compreensão da gestão; ausência de encaminhamento formal, falta de organização quanto à periodicidade, cronograma e planejamento. Quanto ao Núcleo Ampliado de Saúde da Família, foi avaliado seu trabalho na Atenção Básica e a parceria com as Equipes de Saúde da Família. O trabalho em grupos na Atenção Básica traz inúmeras potencialidades e dificuldades, sendo necessário que os profissionais estejam aptos a lidar com tais percalços. Percebeu-se que onde ocorre trabalho multiprofissional bons resultados são colhidos, para tanto, é necessário planejamento conjunto, partindo das necessidades da população.
\end{abstract}

Palavras-chave: Educação em saúde; Atenção primária à saúde; Estrutura de grupo; Adesão do paciente; Promoção da Saúde.

\begin{abstract}
This research aimed to analyze the Brazilian scientific production regarding work in educational groups carried out in Primary Care between 2009 and 2018, highlighting the potential and difficulties encountered by professionals and the contributions of the groups from the implementation of the Expanded Center for Family Health and Primary Care. This is an Integrative Literature Review whose search took place in the Virtual Health Library from the combination of nine keywords in eight intersections, resulting in 220 studies. Eighteen studies were selected, most of which used a qualitative methodology and approached health professionals. As for the place of publication, the Brazilian region with the greatest contribution was the Northeast, whereas in the North and Midwest the theme is little explored. The journal with the greatest contribution was Ciência e Saúde Coletiva. The highlighted potentials were:exchange of experience between users; realization by a multidisciplinary team; link between professional and user; use of community spaces. As difficulties, the following stand out: inadequate structure; low adherence of professionals and users; lack of understanding of management; lack of formal referral, lack of organization regarding periodicity, schedule and planning. As for the Expanded Family Health Center, its work in Primary Care and its partnership with the Family Health Teams was evaluated. Working in groups in Primary Care brings countless potentials and difficulties, making it necessary for professionals to be able to deal with such mishaps. It was noticed that where there is multiprofessional work, good results are collected, therefore, joint planning is necessary.
\end{abstract}

Keywords: Health education; Primary health care; Group structure; Patient compliance; Health promotion.

\section{Resumen}

Esta investigación tuvo como objetivo analizar la producción científica brasileña sobre el trabajo en grupos educativos realizado en Atención Primaria entre 2009 y 2018, destacando las potencialidades y dificultades encontradas por los 
profesionales y los aportes de los grupos a partir de la implementación del Centro Ampliado de Salud de la Familia y Atención primaria. Se trata de una Revisión de Literatura Integrativa cuya búsqueda se realizó en la Biblioteca Virtual en Salud de la combinación de nueve palabras clave en ocho intersecciones, dando como resultado 220 estudios. Se seleccionaron 18 estudios, la mayoría de los cuales utilizaron una metodología cualitativa y se acercaron a los profesionales de la salud. En cuanto al lugar de publicación, la región brasileña con mayor contribución fue el Nordeste, mientras que en el Norte y Medio Oeste el tema está poco explorado. La revista con mayor contribución fue Ciência e Saúde Coletiva. Los potenciales destacados fueron: intercambio de experiencias entre usuarios; realización por un equipo multidisciplinario; vínculo entre profesional y usuario; uso de espacios comunitarios. Como dificultades, se destacan las siguientes: estructura inadecuada; baja adherencia de profesionales y usuarios; falta de comprensión de la gestión; falta de derivación formal, falta de organización en cuanto a periodicidad, cronograma y planificación. En cuanto al Centro Ampliado, se evaluó su trabajo y su asociación con los Equipos de Salud de la Familia. Trabajar en grupo en Atención Primaria conlleva innumerables potencialidades y dificultades, por lo que es necesario que los profesionales sean capaces de afrontar tales percances.

Palabras clave: Educación en salud; Atención primaria de salud; Estructura de grupo; Cooperación del paciente; Promoción de la salud.

\section{Introdução}

A Atenção Básica (AB) é a principal porta de entrada do usuário do Sistema Único de Saúde (SUS) na Rede de Atenção à Saúde (RAS). Conforme descrito na nova Política Nacional de Atenção Básica (PNAB), a AB constitui-se como “o conjunto de ações de saúde individuais, familiares e coletivas que envolvem promoção, prevenção, proteção, diagnóstico, tratamento, reabilitação, redução de danos, cuidados paliativos e vigilância em saúde", sendo estas ações desenvolvidas por equipe multiprofissional e direcionadas à população sob sua responsabilidade (Ministério da Saúde, 2017).

$\mathrm{Na} \mathrm{AB}$ o indivíduo é visto em sua singularidade e âmbito sociocultural a fim de se conseguir a atenção integral. Neste nível de atenção busca-se planejar e implementar ações visando a promoção e proteção da saúde das pessoas, a prevenção de agravos, doenças e riscos (Ministério da Saúde, 2017). A Carta de Ottawa (Organização Mundial da Saúde, 1986) descreve a promoção da saúde como o "processo de capacitação da comunidade para atuar na melhoria de sua qualidade de vida e saúde, incluindo uma maior participação no controle deste processo".

Neste contexto, a Equipe de Saúde da Família (eqSF) é tida como a principal estratégia de atenção à saúde com intuito de reorganizar a AB no Brasil, conforme determina o SUS. É vista como uma estratégia para expandir, qualificar e consolidar a AB já que favorece a reorganização do processo de trabalho ampliando o potencial de resolutividade o que impacta na situação de saúde da população tanto individual quanto coletivamente (Ministério da Saúde, 2017).

Nesta perspectiva e para ampliar a resolutividade aos principais problemas de saúde encontrados na AB, o Ministério da Saúde criou, em 2008, os Núcleos de Apoio à Saúde da Família (NASF) (Ministério da Saúde, 2014). O NASF-AB (Núcleo Ampliado de Saúde da Família e Atenção Básica), assim chamado após publicação da nova PNAB, em 2017, constitui-se de equipe multiprofissional composta por profissionais da saúde de diferentes categorias. Esta equipe complementa o serviço prestado pelas equipes atuantes na AB prestando suporte clínico, pedagógico e sanitário (Ministério da Saúde, 2017).

De acordo com a nova PNAB as ações educativas desenvolvidas devem ser sistematizadas para que interfiram no processo de saúde-doença da população, na construção da autonomia individual e coletiva e na promoção do autocuidado e procura por qualidade de vida pelos indivíduos (Ministério da Saúde, 2017). Várias ações educativas em saúde são desenvolvidas por meio de grupos, com a interação de sujeitos que possuam as mesmas características ou que possam recuperar-se por meio do mesmo cuidado em saúde.

Nesse sentido, os grupos de educação em saúde realizados na AB pelos profissionais da eqSF ou do NASF são fundamentais para a adequada atenção dos usuários. Com base no exposto e visto a importância do trabalho em grupos educativos realizado pelos diversos profissionais na $\mathrm{AB}$, o trabalho de revisão integrativa objetivou analisar a produção científica brasileira referente ao trabalho em grupos educativos realizados na Atenção Básica no período de 2009 a 2018 . A partir da caracterização das publicações, analisaram-se as potencialidades e dificuldades encontradas pelos profissionais da 
Atenção Básica nas atividades em grupos educativos desenvolvidas; e, também, as contribuições dos grupos educativos a partir da implementação do Núcleo Ampliado de Saúde da Família e Atenção Básica (NASF-AB).

\section{Metodologia}

Este estudo é uma Revisão Integrativa. Para sua realização foram seguidas as etapas propostas por Cooper (1984), sendo: construção da questão norteadora; determinação da estratégia de busca na literatura; seleção dos estudos com base nos critérios de inclusão; leitura crítica, avaliação e classificação do conteúdo; análise e interpretação dos resultados.

A construção da questão norteadora do estudo elaborou como pergunta: Quais as características da produção científica brasileira referente ao trabalho em grupos educativos realizados na Atenção Básica no período de 2009 a 2018 ?

Após a delimitação da questão norteadora, ocorreu a busca nas bases de dados que compõem a Biblioteca Virtual em Saúde (BVS), pois esta base de dados reúne dados de portais como o SCIELO E LILACS. Não foram utilizadas bases de dados como a PubMed e o Medline, pois o NASF é uma estratégia dentro da atenção básica brasileira, compreendendo que as publicações estejam mais presentes na língua portuguesa. Para realizar a busca dos estudos, foram combinadas nove palavraschave, oito delas presentes nos Descritores em Ciências de Saúde (DeCS) sendo: Adesão do paciente, Atenção Primária à Saúde, Autocuidado, Educação em saúde, Estratégia Saúde da Família, Estrutura de grupo, Grupos de apoio, Núcleo de Apoio à Saúde da Família e Promoção da saúde. Apenas Núcleo de Apoio à Saúde da Família não é considerado descritor ou termo no DeCS, sendo incluído visto sua relação com o tema do presente estudo. A Figura 1 apresenta os cruzamentos realizados a partir dos descritores.

Figura 1 - Cruzamentos realizados para busca de estudos na Biblioteca Virtual em Saúde.
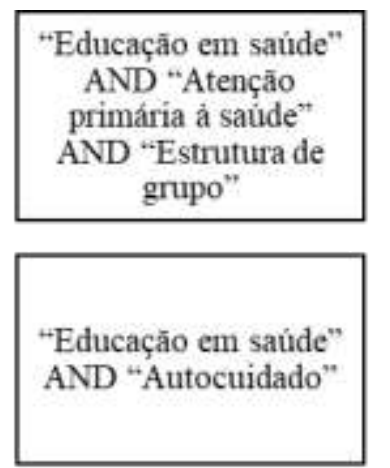
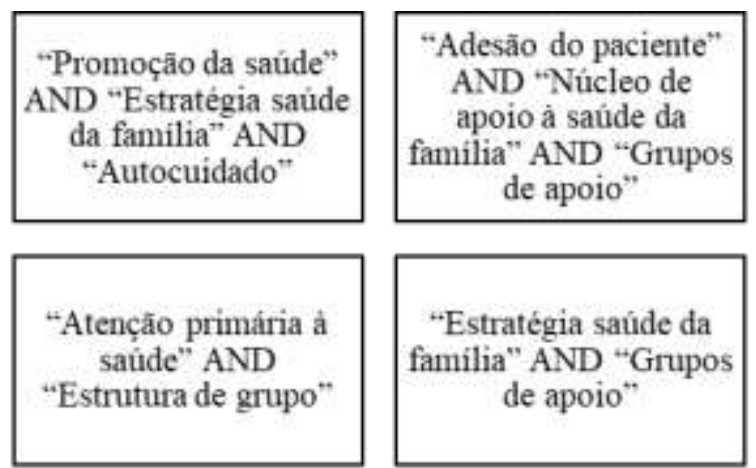
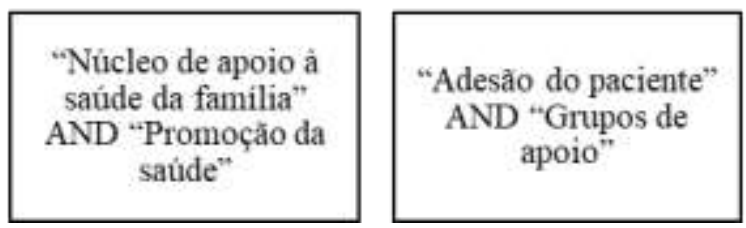

Fonte: Autores (2021).

Como critérios de inclusão adotou-se: trabalhos publicados no formato de artigos científicos originais, teses e dissertações, trabalhos resultantes de pesquisa acadêmica, trabalhos cujos objetivos guardem relação com o objeto deste estudo, trabalhos publicados no idioma português, nos últimos 10 anos, considerando o período de 2009 a 2018, trabalhos disponíveis on-line na forma completa e sem custos. Os critérios de exclusão foram artigos de revisão, projetos de pesquisa, cartilha/folder, dados secundários. Todos estes textos foram excluídos, pois não respondiam à pergunta norteadora desta revisão. 
A busca foi realizada em 01/12/2019 com base nos oito cruzamentos realizados a partir dos descritores selecionados para o estudo. A busca resultou em 220 estudos que foram importados para o software Endnote.

Para análise dos estudos, foram detalhadas em uma tabela algumas informações referentes às publicações, sendo: título, ano, autores, objetivo, aspectos metodológicos, tema, principais resultados e conclusões que serão detalhadas nos resultados e discussão.

\section{Resultados e Discussão}

A busca resultou em 220 estudos. Após exclusão dos 79 estudos duplicados restaram 141 estudos para leitura exploratória, sendo que destes, 123 foram excluídos e 18 foram selecionados para compor a presente revisão. A Figura 2 demonstra o processo de construção da amostra.

Figura 2 - Processo de construção da amostra da presente revisão.

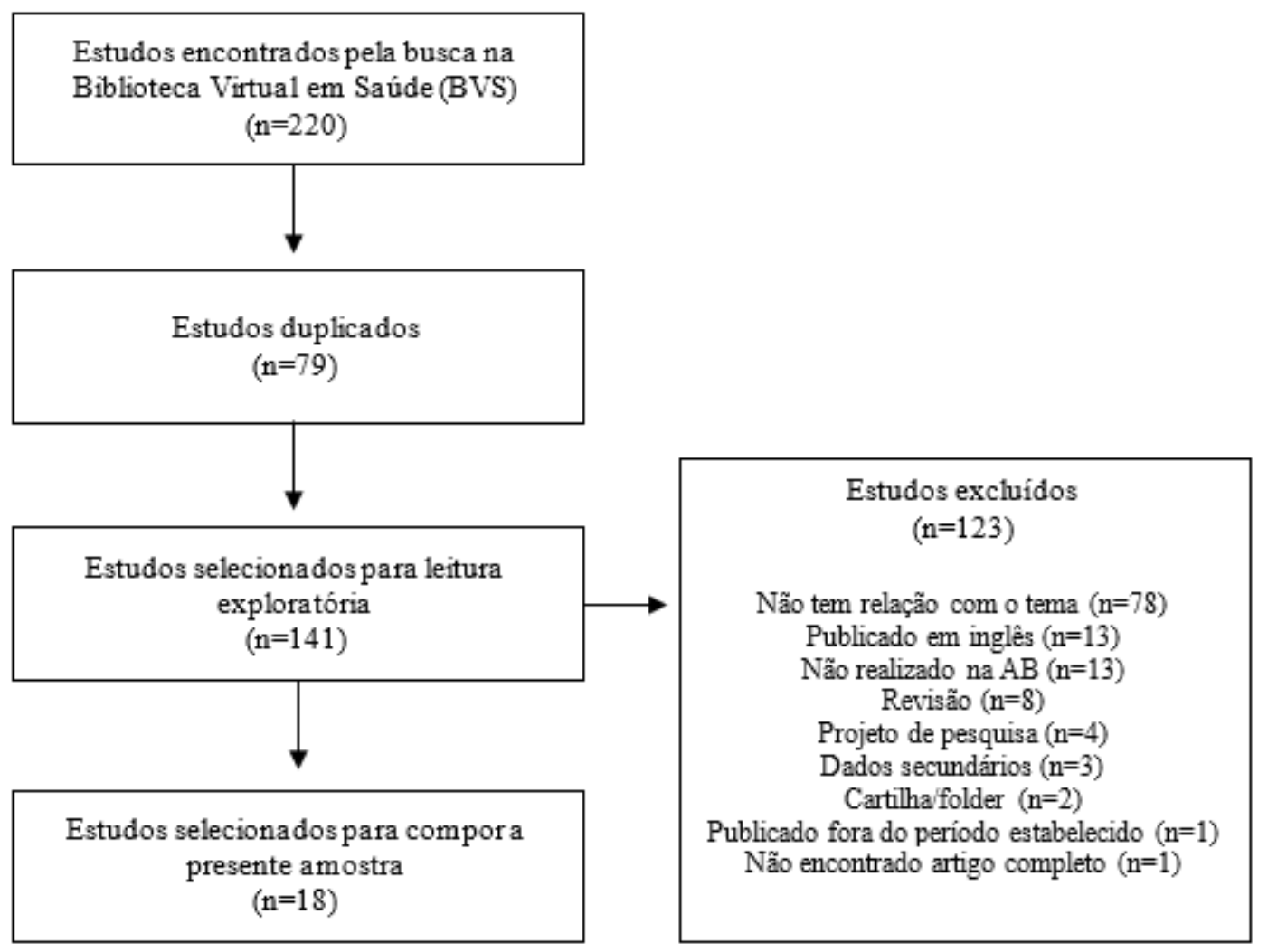

Fonte: Autores (2021).

\subsection{Características das publicações}

A leitura crítica das publicações foi realizada pelas autoras do trabalho, sendo enviado a um colaborador para decidir algum aspecto que não estava claro na leitura do texto. Ao final da leitura crítica, avaliação e classificação do conteúdo, restaram 18 estudos para a análise e interpretação dos resultados. O Quadro 1 caracteriza tais estudos e o Quadro 2 aponta as principais contribuições de cada estudo a presente pesquisa. 
Quadro 1 - Caracterização dos estudos incluídos na amostra da presente revisão.

\begin{tabular}{|c|c|c|c|c|}
\hline $\begin{array}{c}\text { AUTOR E } \\
\text { REVISTA/INSTITUIÇÃO }\end{array}$ & $\begin{array}{c}\text { ANO DE } \\
\text { PUBLICAÇÃO }\end{array}$ & $\begin{array}{c}\text { LOCAL DE } \\
\text { CONDUÇÃO }\end{array}$ & TIPO DE ESTUDO & $\begin{array}{c}\text { PUBLICO } \\
\text { ESTUDADO }\end{array}$ \\
\hline $\begin{array}{c}\text { MAIA et al. } \\
\text { Ciência Plural } \\
\end{array}$ & 2018 & Pau dos Ferros - RN & $\begin{array}{c}\text { Exploratório e descritivo, de } \\
\text { natureza qualitativa }\end{array}$ & $\begin{array}{l}\text { Profissionais da } \\
\text { equipe de saúde }\end{array}$ \\
\hline $\begin{array}{l}\text { MEDEIROS et al. } \\
\text { Revista de pesquisa: Cuidado é } \\
\text { Fundamental online }\end{array}$ & 2012 & Garuva - SC & $\begin{array}{c}\text { Pesquisa qualitativa do tipo } \\
\text { exploratório descritiva }\end{array}$ & $\begin{array}{c}\text { Usuários } \\
\text { hipertensos }\end{array}$ \\
\hline $\begin{array}{c}\text { MELO \& CASTRO } \\
\text { Ciência e Saúde Coletiva }\end{array}$ & 2017 & São Paulo - SP & Estudo descritivo, transversal & Farmacêutico \\
\hline $\begin{array}{c}\text { MELO, MELO \& VILAR } \\
\text { Ciência Plural } \\
\end{array}$ & 2018 & Natal - RN & Estudo qualitativo exploratório & $\begin{array}{l}\text { Profissionais da } \\
\text { equipe e usuários }\end{array}$ \\
\hline $\begin{array}{l}\text { ONOCKO-CAMPOS et al. } \\
\text { Revista de Saúde Pública }\end{array}$ & 2012 & Campinas - SP & $\begin{array}{c}\text { Estudo avaliativo, participativo, } \\
\text { predominantemente } \\
\text { qualitativo } \\
\end{array}$ & $\begin{array}{c}\text { Profissionais da } \\
\text { equipe de saúde e } \\
\text { usuários }\end{array}$ \\
\hline $\begin{array}{c}\text { PIMENTEL et al. } \\
\text { Ciência e Saúde Coletiva }\end{array}$ & 2014 & $\begin{array}{c}\text { Belém - PA } \\
\text { Maceió - AL } \\
\text { Goiânia - GO } \\
\text { São Paulo - SP } \\
\text { Maringá - PR } \\
\end{array}$ & Estudo qualitativo & $\begin{array}{l}\text { Profissionais da } \\
\text { saúde }\end{array}$ \\
\hline $\begin{array}{c}\text { ROCHA et al. } \\
\text { Revista Gaúcha de Enfermagem }\end{array}$ & 2013 & João Pessoa - PB & $\begin{array}{c}\text { Pesquisa documental de caráter } \\
\text { descritivo }\end{array}$ & $\begin{array}{c}\text { Pesquisa } \\
\text { documental com } \\
\text { foco nos usuários }\end{array}$ \\
\hline $\begin{array}{l}\text { SILVA et al. } \\
\text { Ciência Plural }\end{array}$ & 2018 & Maceió - AL & Estudo descritivo, qualitativo & $\begin{array}{c}\text { Usuários } \\
\text { hipertensos e } \\
\text { diabéticos } \\
\end{array}$ \\
\hline $\begin{array}{c}\text { SILVA et al. } \\
\text { Ciência Plural }\end{array}$ & 2017 & Assú - RN & Estudo descritivo, qualitativo & Enfermeiras \\
\hline $\begin{array}{l}\text { MAFFACCIOLLI \& LOPES } \\
\text { Ciência e Saúde Coletiva }\end{array}$ & 2011 & Porto Alegre - RS & $\begin{array}{c}\text { Estudo exploratório com } \\
\text { abordagem quanti-qualitativa }\end{array}$ & $\begin{array}{l}\text { Profissionais da } \\
\text { equipe de saúde }\end{array}$ \\
\hline $\begin{array}{c}\text { GONÇALVES et al. } \\
\text { Revista Brasileira de Saúde } \\
\text { Ocupacional }\end{array}$ & 2015 & São Paulo - SP & Estudo de caso quantitativo & $\begin{array}{l}\text { Profissionais da } \\
\text { equipe de saúde }\end{array}$ \\
\hline $\begin{array}{c}\text { COSTA, SILVA \& } \\
\text { CARVALHO } \\
\text { Ciência e Saúde Coletiva } \\
\end{array}$ & 2011 & Recife - PE & Quantitativo & $\begin{array}{l}\text { Profissionais da } \\
\text { equipe }\end{array}$ \\
\hline $\begin{array}{c}\text { COSTA et al. } \\
\text { Ciência e Saúde Coletiva }\end{array}$ & 2011 & Teixeiras - MG & $\begin{array}{l}\text { Estudo observacional de corte } \\
\text { transversal de abordagem quanti - } \\
\text { qualitativa }\end{array}$ & $\begin{array}{l}\text { Usuárias mães de } \\
\text { crianças escolares }\end{array}$ \\
\hline $\begin{array}{l}\text { COSTA et al. } \\
\text { CoDAS }\end{array}$ & 2013 & Paraíba, Brasil & Estudo qualitativo & Fonoaudiólogo \\
\hline $\begin{array}{c}\text { BRITO } \\
\text { Centro de Pesquisas Aggeu } \\
\text { Magalhães, Fiocruz }\end{array}$ & 2016 & João Pessoa - PB & Tese. Estudo de caso quantitativo & $\begin{array}{l}\text { Profissionais da } \\
\text { equipe de saúde }\end{array}$ \\
\hline $\begin{array}{c}\text { CÁRDENAS } \\
\text { Faculdade de Saúde Pública - } \\
\text { USP } \\
\end{array}$ & 2013 & $\begin{array}{c}\text { Cidades de São Paulo } \\
\text { no Brasil e Bogotá na } \\
\text { Colômbia }\end{array}$ & $\begin{array}{c}\text { Dissertação. Pesquisa qualitativa, } \\
\text { descritiva com metodologia } \\
\text { comparativa }\end{array}$ & Nutricionistas \\
\hline $\begin{array}{c}\text { SILVA } \\
\text { UERJ - Centro Biomédico - } \\
\text { Faculdade de Enfermagem }\end{array}$ & 2010 & Rio de Janeiro - RJ & $\begin{array}{c}\text { Dissertação. Abordagem } \\
\text { qualitativa com caráter descritivo }\end{array}$ & $\begin{array}{l}\text { Profissionais da } \\
\text { equipe de saúde }\end{array}$ \\
\hline $\begin{array}{c}\text { GOMES } \\
\text { UERJ - Centro Biomédico - } \\
\text { Faculdade de Enfermagem }\end{array}$ & 2017 & Rio de Janeiro - RJ & $\begin{array}{c}\text { Dissertação - estudo de caso } \\
\text { qualitativo }\end{array}$ & $\begin{array}{l}\text { Profissionais da } \\
\text { equipe de saúde }\end{array}$ \\
\hline
\end{tabular}

Fonte: Autores (2021). 
Quadro 2 - Principais contribuições de cada estudo a presente pesquisa.

\begin{tabular}{|c|c|c|}
\hline AUTOR E ANO & CONTRIBUIÇÕES & CONCLUSÕES \\
\hline MAIA et al., 2018 & $\begin{array}{l}\text { - Educação em saúde vista como forma de evitar } \\
\text { adoecimento. } \\
\text { - Palestras realizadas nas comunidades. } \\
\text { - Falta de cronograma organizado, baixa adesão e } \\
\text { resistência de profissionais. } \\
\text { - Interação entre profissionais e usuários e troca } \\
\text { de experiências entre usuários. }\end{array}$ & $\begin{array}{l}\text { Ações não têm resultados esperados } \\
\text { pois são realizadas em moldes } \\
\text { tradicionais. Importante realizar } \\
\text { atividades que possibilitem ao usuário } \\
\text { pensar sobre seu meio social, sua vida } \\
\text { e saúde. }\end{array}$ \\
\hline MEDEIROS et al., 2012 & $\begin{array}{l}\text { Unidade de saúde e espaço do grupo considerados } \\
\text { importantes para o controle das patologias. }\end{array}$ & $\begin{array}{l}\text { Usuários não conseguem seguir } \\
\text { recomendações todo o tempo. Deve } \\
\text { haver incentivo da Equipe para o } \\
\text { cuidado. }\end{array}$ \\
\hline MELO \& CASTRO, 2017 & $\begin{array}{c}\text { - O farmacêutico realiza educação em saúde } \\
\text { voltada ao uso contínuo e armazenamento de } \\
\text { medicamentos, riscos da automedicação, grupo de } \\
\text { controle do tabagismo. } \\
\text { - Ofertados } 14 \text { grupos, abrangendo } 323 \\
\text { participantes. }\end{array}$ & $\begin{array}{l}\text { O farmacêutico tem papel relevante } \\
\text { para minimizar problemas } \\
\text { relacionados a medicamentos sendo } \\
\text { fundamental a sua presença nas } \\
\text { intervenções realizadas. }\end{array}$ \\
\hline $\begin{array}{c}\text { MELO, MELO \& VILAR, } \\
2018\end{array}$ & $\begin{array}{l}\text { - Grupos operativos foram o } 3^{\circ} \text { tipo mais } \\
\text { identificado de redes. } \\
\text { - Grupos considerados importantes por usuários e } \\
\text { profissionais por promover melhora na patologia } \\
\text { e facilitar a transmissão de informações, } \\
\text { atingindo mais pessoas. }\end{array}$ & $\begin{array}{l}\text { Valorizar as redes sociais locais pode } \\
\text { representar uma adesão maior às } \\
\text { atividades coletivas voltadas à } \\
\text { promoção da saúde e fortalecer as } \\
\text { atividades oferecidas pela unidade de } \\
\text { saúde. }\end{array}$ \\
\hline $\begin{array}{l}\text { ONOCKO-CAMPOS et al., } \\
2012\end{array}$ & $\begin{array}{l}\text { - Grupo e parceria com outros serviços são } \\
\text { importantes. } \\
\text { - Não há divulgação e encaminhamento e } \\
\text { comunidade tem dificuldade em aderir aos } \\
\text { grupos, devido cultura do assistencialismo; } \\
\text { - Assistência à saúde é fator de impedimento à } \\
\text { realização de ações de prevenção e promoção. } \\
\text { - Grupos ficam sob responsabilidade do ACS. }\end{array}$ & $\begin{array}{c}\text { Mecanismos de fixação de } \\
\text { profissionais na AB são necessários. } \\
\text { Os ACS são indispensáveis na } \\
\text { viabilização do trabalho territorial. }\end{array}$ \\
\hline PIMENTEL et al., 2014 & $\begin{array}{l}\text { - Dificuldades: falta de estrutura física e } \\
\text { materiais, de conhecimento técnico e do } \\
\text { nutricionista; baixa assiduidade do usuário ao } \\
\text { grupo; falta de articulação da equipe. } \\
\text { - Para superar: incluir nutricionista; trabalho } \\
\text { multidisciplinar; articulação com escola; } \\
\text { melhorias no espaço físico; treinamentos. }\end{array}$ & $\begin{array}{l}\text { A AB é um espaço privilegiado para } \\
\text { ações de alimentação e nutrição. Cabe } \\
\text { pensar na inserção de profissionais } \\
\text { qualificados em número adequado } \\
\text { para desenvolver ações de } \\
\text { alimentação e nutrição. }\end{array}$ \\
\hline ROCHA et al., 2013 & $\begin{array}{l}\text { - Principais temas abordados: estresse e conflitos } \\
\text { familiares. } \\
\text { - Grupo é percebido como positivo pelos } \\
\text { usuários. }\end{array}$ & $\begin{array}{l}\text { TCI permite construir relações que } \\
\text { promovem apoio emocional, } \\
\text { fortalecimento de vínculo e redução } \\
\text { na exclusão social. Ferramenta de } \\
\text { baixo custo com resultados positivos } \\
\text { que precisam ser divulgados para } \\
\text { fortalecer a estratégia. }\end{array}$ \\
\hline SILVA et al., 2018 & $\begin{array}{l}\text { - Intervenção com mulheres em grupo de } \\
\text { atividade física. } \\
\text { - Usuárias ativas, participantes e interessadas em } \\
\text { evitar agravos das patologias e dispostas a colocar } \\
\text { as orientações em prática. }\end{array}$ & $\begin{array}{l}\text { Demonstrada relevância de planejar } \\
\text { as ações em equipe e também a } \\
\text { humanização no SUS. A educação em } \\
\text { saúde tem papel fundamental na } \\
\text { formação de profissionais. }\end{array}$ \\
\hline SILVA et al., 2017 & $\begin{array}{c}\text { - Ações realizadas em campanhas do MS e no } \\
\text { grupo hiperdia. } \\
\text { - Falta de periodicidade das ações. } \\
\text { - Atividades verticalizadas pautadas no modelo } \\
\text { bancário. }\end{array}$ & $\begin{array}{l}\text { Metodologia utilizada não oportuniza } \\
\text { a mudança de hábitos e contribui para } \\
\text { que se perpetuem sujeitos passivos. }\end{array}$ \\
\hline MAFFACCIOLLI \& LOPES, & - Grupos proporcionam esclarecimento, troca de & A maioria dos profissionais \\
\hline
\end{tabular}




\begin{tabular}{|c|c|c|}
\hline 2011 & $\begin{array}{c}\text { experiências, autocuidado, prevenção, } \\
\text { valorização da equipe pelos usuários, otimização } \\
\text { do vínculo e horizontalização. } \\
\text { - Grupos desenvolvidos por equipe } \\
\text { multiprofissional. } \\
\text { - Atividades grupais secundárias a atendimentos } \\
\text { individuais e ações burocráticas. } \\
\text { - Ações voltadas principalmente às práticas } \\
\text { oficiais e atreladas à entrega de receitas ou } \\
\text { medicamentos. } \\
\text { - Espaço físico desfavorável. }\end{array}$ & $\begin{array}{l}\text { desenvolviam atividades de grupo. Os } \\
\text { grupos podem caracterizar-se como } \\
\text { oportunos espaços de esclarecimento } \\
\text { e troca de conhecimento, com práticas } \\
\text { voltadas ao autocuidado e à } \\
\text { prevenção de agravos à saúde, } \\
\text { promovendo reorientação do modelo } \\
\text { de assistência à saúde vigente pois } \\
\text { reinventa a relação de pacientes e } \\
\text { profissionais. }\end{array}$ \\
\hline GONÇALVES et al., 2015 & $\begin{array}{l}\text { - Planejamento conjunto entre NASF e ESF } \\
\text { essencial para ampliar o olhar e o escopo de ações } \\
\text { e responsabilização sobre as atividades. } \\
\text { - Atividades realizadas na UBS e outros locais do } \\
\text { território e muitas vezes centralizados no NASF. } \\
\text { - Grupos realizados prioritariamente à tarde por } \\
\text { maior adesão da população, embora dificulte } \\
\text { participação de profissionais do turno da manhã. } \\
\text { - Dificuldades relacionadas à estrutura material e } \\
\text { física; meios de transporte para deslocamento de } \\
\text { profissionais. }\end{array}$ & $\begin{array}{c}\text { NASF e ESF precisam trabalhar } \\
\text { juntas, entretanto existem diferenças } \\
\text { nos processos de trabalho destas } \\
\text { equipes que influenciam esta parceria. }\end{array}$ \\
\hline $\begin{array}{l}\text { COSTA, SILVA \& } \\
\text { CARVALHO, } 2011\end{array}$ & $\begin{array}{l}\text { - Falta de materiais educativos, insumos, } \\
\text { manutenção de equipamentos, infraestrutura. } \\
\text { - Ausência de diretrizes para ações de prevenção } \\
\text { e controle contribuem para baixa execução. } \\
\text { - Baixa adesão da equipe às atividades. }\end{array}$ & $\begin{array}{l}\text { Adotar medidas adequadas pode } \\
\text { reduzir o efeito socioeconômico que } \\
\text { este agravo pode provocar, } \\
\text { colaborando com a melhora da } \\
\text { qualidade de vida dos usuários. }\end{array}$ \\
\hline COSTA et al., 2011 & $\begin{array}{c}\text { - Baixa inserção das mães nas atividades e } \\
\text { dificuldade dos profissionais em executá-las. } \\
\text { - Mães relatam inexistência ou desconhecimento } \\
\text { sobre as atividades. } \\
\text { - Comunicação paternalista, atividades } \\
\text { fundamentadas no modelo tradicional. } \\
\text { - Falta de espaço físico e planejamento de ações } \\
\text { para o grupo infantil; pouca parceria com outros } \\
\text { setores. }\end{array}$ & $\begin{array}{l}\text { Realizam-se poucas atividades de } \\
\text { prevenção e promoção da saúde o que } \\
\text { evidencia que em muitos momentos o } \\
\text { Programa Saúde da Família (PSF) } \\
\text { atua como suporte ao hospital. O } \\
\text { espaço físico insuficiente dificulta a } \\
\text { realização de ações de educação em } \\
\text { saúde. }\end{array}$ \\
\hline COSTA et al., 2013 & $\begin{array}{c}\text { - Principal recurso foi a palestra, sem efetiva } \\
\text { participação do usuário. } \\
\text { - Dificuldades em compartilhar ações com ESF, e } \\
\text { na compreensão destas ações pela gestão. } \\
\text { - Pouca realização de ações preventivas devido } \\
\text { baixo número de equipes NASF e modelo } \\
\text { intermunicipal. } \\
\text { - Profissionais defendem prática preventiva e } \\
\text { desenvolvem basicamente ações curativas } \\
\text { individuais. } \\
\text { - Formação de grupos conjuntamente entre } \\
\text { profissionais NASF. }\end{array}$ & $\begin{array}{l}\text { Percebe-se que os desafios } \\
\text { apresentados repercutem nas } \\
\text { atividades desenvolvidas, sendo estas } \\
\text { pouco condizentes com o conceito de } \\
\text { promoção da saúde e de atuação do } \\
\text { NASF propostas pelo MS. }\end{array}$ \\
\hline BRITO, 2016 & $\begin{array}{l}\text { - A maioria dos profissionais de nível superior } \\
\text { está envolvida em alguma atividade de grupo na } \\
\text { semana. } \\
\text { - Enfermeiros e dentistas participam de mais } \\
\text { atividades em grupo comparados aos médicos, o } \\
\text { que pode ser devido à visão biologicista com foco } \\
\text { no atendimento individual e curativo. }\end{array}$ & $\begin{array}{l}\text { Pouco tempo dedicado às atividades } \\
\text { de prevenção, promoção e educação } \\
\text { em saúde. Maior envolvimento dos } \\
\text { profissionais pode qualificar a } \\
\text { assistência através da abordagem } \\
\text { interprofissional. Isto deve ser } \\
\text { trabalhado com os profissionais e } \\
\text { estudantes. }\end{array}$ \\
\hline CÁRDENAS, 2013 & $\begin{array}{l}\text { Grupos em São Paulo focados na doença ou ciclo } \\
\text { da vida; em Bogotá em programas pré- } \\
\text { estabelecidos. Temas baseados no interesse dos }\end{array}$ & $\begin{array}{l}\text { Temáticas estavam de acordo às } \\
\text { características dos grupos. É } \\
\text { fundamental que os temas tenham }\end{array}$ \\
\hline
\end{tabular}




\begin{tabular}{|c|c|c|}
\hline & $\begin{array}{c}\text { participantes, documentos técnicos, objetivo do } \\
\text { grupo, diretrizes pré-estabelecidas pelas } \\
\text { secretarias de saúde e com auxílio dos } \\
\text { profissionais. }\end{array}$ & $\begin{array}{l}\text { significado para os participantes e que } \\
\text { visem resultados específicos à } \\
\text { população envolvida. }\end{array}$ \\
\hline SILVA, 2010 & $\begin{array}{c}\text { - Prática educativa não faz parte do processo de } \\
\text { trabalho do médico. } \\
\text { - Infraestrutura inadequada; falhas na divulgação } \\
\text { e garantia de espaço na agenda dos profissionais; } \\
\text { sobrecarga de trabalho; dificuldade no } \\
\text { entrosamento da equipe. Não há planejamento } \\
\text { formal. } \\
\text { - Desinteresse do usuário/falta de compreensão } \\
\text { sobre o modelo PSF. Desinteresse do } \\
\text { profissional. } \\
\text { - Vínculo entre profissional e usuário favorável } \\
\text { ao desenvolvimento das ações. } \\
\text { - Protagonismo do ACS. } \\
\text { - Atividade ocorre em diversos locais. Violência é } \\
\text { fator de risco para sua realização em espaços } \\
\text { públicos. } \\
\text { - Temas escolhidos conforme percepção da } \\
\text { equipe sobre a comunidade. }\end{array}$ & $\begin{array}{l}\text { Não é percebida responsabilização da } \\
\text { equipe pelas atividades educativas. O } \\
\text { enfermeiro se destaca na coordenação } \\
\text { das atividades e o ACS as executa. } \\
\text { Predomínio do modelo bancário. }\end{array}$ \\
\hline GOMES, 2017 & $\begin{array}{l}\text { - Ausência da enfermagem nos grupos. Médicos } \\
\text { encaminham usuários aos grupos. } \\
\text { - Grupos ocorrem no auditório da unidade } \\
\text { (espaço adequado) no horário marcado. } \\
\text { - 52\% dos idosos entrevistados afirmaram } \\
\text { participar de um ou mais grupos. }\end{array}$ & $\begin{array}{l}\text { Os idosos avaliam positivamente os } \\
\text { serviços ofertados na UBS. A equipe } \\
\text { trabalha de forma reativa e não } \\
\text { proativa, com ações baseadas no } \\
\text { modelo biomédico. }\end{array}$ \\
\hline
\end{tabular}

Fonte: Autores (2021).

A caracterização dos artigos publicados mostra que em relação à abordagem metodológica, 10 estudos tiveram abordagem qualitativa (55,4\%); quatro quantitativo (22,2\%); dois estudos de caso qualitativo (11,1\%); um estudo transversal (5,6\%); um estudo documental descritivo (5,6\%). Quanto ao público-alvo, 8 estudos abordaram profissionais da equipe de saúde $(44,5 \%)$; quatro abordaram categorias isoladas de profissionais (22,2\%), dois estudos abordaram profissionais e usuários do sistema de saúde $(11,1 \%)$; dois estudos abordaram apenas usuários do sistema de saúde $(11,1 \%)$; e dois estudos realizaram coleta documental $(11,1 \%)$.

Em relação aos anos de publicação, foram encontrados artigos publicados entre os anos de 2010 e 2018 , sendo sua distribuição semelhante ao longo dos anos, variando de 1 a 3 artigos ao ano. Quanto ao local de realização do estudo, percebeu-se que o estado com maior número de estudos encontrados foi São Paulo com quatro estudos (21,9\%) sendo que em um deles também houve coleta de dados em Bogotá na Colômbia; seguido por Rio Grande do Norte com três estudos (16,7\%); e Paraíba também com três estudos (16,7\%); Rio de Janeiro com dois estudos (11,1\%), Santa Catarina, Rio Grande do Sul, Alagoas, Pernambuco e Minas Gerais com um estudo (5,6\%) em cada estado. Ainda, um estudo foi realizado em 5 municípios, um representante de cada região do Brasil (5,6\%).

O periódico que somou maior número de publicações foi Ciência e Saúde Coletiva com cinco estudos $(27,5 \%)$, seguido de Ciência Plural com quatro estudos (22,2\%). Revista de pesquisa: Cuidado é Fundamental online, Revista de Saúde Pública, Revista Gaúcha de Enfermagem, Revista Brasileira de Saúde Ocupacional, e CoDAS (Sociedade Brasileira de Fonoaudiologia) contribuíram com um estudo cada, correspondendo a 5,6\% para cada periódico. Em relação às quatro dissertações e tese incluídas nesta revisão, duas foram vinculadas à Universidade do Estado do Rio de Janeiro (11,1\%); uma à Universidade de São Paulo (5,6\%); e uma ao Centro de Pesquisas Aggeu Magalhães, da Fundação Oswaldo Cruz (5,6\%). 
Observando este perfil percebe-se que a maioria dos estudos utilizou abordagem qualitativa e enfocou profissionais de saúde em sua coleta de dados. Em relação ao local de publicação, observa-se que a região brasileira que contribuiu com o maior número de estudos foi a nordeste, seguida da região sudeste, sendo que nas regiões norte e centro-oeste o tema é pouco explorado. O periódico que trouxe maior contribuição foi Ciência e Saúde Coletiva, o que pode ser devido a este ser publicado pela Associação Brasileira de Saúde Coletiva (ABRASCO).

\subsection{Potencialidades na realização de grupos na Atenção Básica}

Quando se trata das potencialidades do trabalho educativo em grupos, é possível perceber em quatro dos artigos estudados que os sujeitos entrevistados percebem o espaço do grupo como importante (Medeiros et al., 2012; Melo, Melo \& Vilar, 2018; Onocko-Campos et al., 2012; Rocha et al., 2013). O espaço grupal é valorizado também devido à troca de experiência entre os usuários (Maffacciolli \& Lopes, 2011; Maia et al., 2018).

Teixeira et al. (2017) que realizaram estudo acerca da percepção de profissionais da AB sobre grupos realizados com gestantes, perceberam que os profissionais entrevistados reconhecem a atividade como relevante e proveitosa já que possibilita a troca de informações entre profissionais e usuários e, além disso, é um espaço que permite o esclarecimento de dúvidas das gestantes. Luz et al. (2019) concluíram com seu estudo que atividades educativas em grupo favorecem a aproximação entre gestantes e profissionais e tais atividades promovem associar esclarecimentos e ações para prevenir agravos na gestação.

Em estudo realizado acerca do uso de plantas medicinais por usuários de determinada unidade de saúde concluiu-se que tanto as rodas de conversa quanto as visitas domiciliares realizadas a partir do referido projeto de educação em saúde favoreceram a formação de vínculo e troca de experiência entre profissionais e usuários (Dantas et al., 2019).

Friedrich et al. (2018) constataram que o vínculo formado entre profissionais e usuários em atividades de grupo auxiliou no fortalecimento do cuidado. Ainda para os mesmos autores o vínculo constituiu-se através da conversa, incentivo e convivência realizados no grupo e devido a isto foi considerado motivo de adesão e permanência no grupo. Foi citada ainda a troca de experiências que aconteceu no grupo e que com isto, os usuários puderam ampliar seu conhecimento sobre assuntos relacionados a saúde.

Outros pontos positivos destacados foram a realização das atividades de grupo por equipe multiprofissional (Costa et al., 2013; Maffacciolli \& Lopes, 2011); o vínculo entre profissional e usuário como fator favorável ao desenvolvimento de ações educativas (Silva, 2010); e a utilização de espaços da comunidade para desenvolver as ações (Maia et al., 2018). Cabe destacar que Silva (2010) observou que a violência no território estudado foi considerada fator de risco para a realização de atividades educativas em espaços da comunidade.

Para Diógenes et al. (2016) ficou claro nos discursos dos profissionais entrevistados que as atividades em grupo são de fundamental importância por promoverem, dentre outros aspectos, o conhecimento, relaxamento, socialização e fortalecimento de vínculo. Domingues, Pinto e Pereira (2018) concluíram que formar vínculo é essencial para que os usuários expressem seus anseios.

Em estudo realizado por Almeida et al. (2017) cerca de atividade em grupo multiprofissional de educação em saúde com foco na melhora da alimentação dos participantes percebeu-se que muitos usuários relataram seus problemas de saúde como motivação para buscar ajuda na referida atividade. Citaram ainda, a falta de conhecimento sobre alimentação saudável e de habilidade para executar preparações mais saudáveis. Entretanto, o ponto positivo mais citado foi o fato de a atividade de grupo partir de uma dinâmica diferente das tradicionais consultas. Destaca-se que tal atividade foi desenvolvida na Sede da Associação de Moradores do bairro, devido a disponibilidade de estrutura para as oficinas culinárias. 
Para Matias (2017, p. 96) "o grupo se caracteriza como um espaço terapêutico, local de ensino e aprendizado com o outro, espaço para reflexão do movimento, expressão e afirmação da vida". O grupo acaba por ser um espaço que oportuniza atingir objetivos, transformando a vida e formando novas redes.

Bertoncello (2018) entende os grupos como ferramentas educativas com potencial terapêutico, portanto faz-se necessário entender tais ações como promotoras de saúde bem como olhar para aqueles que às desenvolvem otimizando tal estratégia.

Conforme afirmam Facchini, Tomasi e Dilélio (2018) nos últimos anos houve aumento na oferta de ações e de serviços decorrentes do significativo crescimento e da manutenção da cobertura da ESF, o que impactou positivamente na saúde das pessoas.

\subsection{Dificuldades na realização de grupos na Atenção Básica}

Sobre as dificuldades encontradas para a realização de atividades em grupo, as relacionadas à estrutura física para desenvolvimento das ações foram citadas por sete publicações (Silva, 2010; Costa et al., 2011; Costa, Silva \& Carvalho, 2011; Gonçalves et al., 2015; Maffacciolli \& Lopes, 2011; Pimentel et al., 2014; Onocko-Campos et al., 2012). Em contrapartida, Gomes (2017) observou na unidade estudada, estrutura adequada para a realização de atividades de grupo, sendo um auditório com espaço adequado e climatizado com cadeiras confortáveis. É importante ressaltar que a referida unidade é considerada mista, já que o Centro Municipal de Saúde e Estratégia Saúde da Família funcionam no mesmo prédio.

Gestantes entrevistadas por Domingues, Pinto e Pereira (2018) sugeriram, quando questionadas sobre o que poderia ser melhorado na atividade de grupo em que participaram, que houvesse melhoria do espaço físico, além de participação de seu cônjuge na atividade.

Conforme afirmam Melo et al. (2018) a expansão da ESF, criação dos NASF e ampliação de Equipes de Saúde Bucal (ESB) marcaram os anos 2000, porém, muitos problemas persistiram, dentre eles a inadequação de infraestrutura, o modelo assistencial, subfinanciamento e problemas relativos a atração de profissionais médicos para atuarem na AB.

Ainda sobre as dificuldades, três dos estudos avaliados citam a baixa adesão da equipe às atividades como uma dificuldade (Silva, 2010; Maia et al., 2018; Costa, Silva \& Carvalho, 2011) e um estudo relata dificuldade de compreensão por parte da gestão em relação às atividades educativas em grupo (Costa et al., 2013). Brito (2016) percebeu que embora as atividades de prevenção, promoção e educação em saúde sejam indicadas pelos profissionais da equipe, há pouco tempo da jornada semanal de trabalho destinada à estas ações.

Em estudo realizado por Souza e Tyrrell (2016) com enfermeiros atuantes na AB também é evidenciado como dificuldade para a realização das atividades educativas em grupo a ausência de outros profissionais da equipe, ficando a atividade apenas a cargo do enfermeiro.

Matias (2017) afirma que o grupo como ferramenta de cuidado a ser utilizado na AB precisa ainda, ser mais bem entendido e explorado pelos profissionais que atuam na ponta, bem como pelos gestores municipais, já que se mostra um dispositivo disparador do cuidado em rede e do cuidar de si.

Friedrich et al. (2018) concluíram com seu estudo que as atividades de grupo são uma ferramenta importante para a promoção da saúde na $\mathrm{AB}$, impactando positivamente tanto nas condições clínicas, quanto nas condições sociais e afetivas dos usuários e por consequência melhorando sua qualidade de vida.

Fernandes, Souza e Rodrigues (2019) perceberam que o grupo se constitui como espaço de aprendizagem, de convivência e de socialização. Pode se constituir como importante ferramenta para inserção social e manutenção da saúde dos usuários refletindo em melhor qualidade de vida, repercutindo também nas famílias, amigos, trabalho e na sociedade como um todo. 
Usuários participantes de atividades grupais entrevistados por Santos (2018) descreveram como fragilidade da ação a necessidade por atenção individualizada, relatando que a falta de informações individualizadas pode ter influenciado para o não alcance de seus objetivos. Em contrapartida, Matias (2017) percebeu com seu estudo que os profissionais prestavam atenção às individualidades dos usuários participantes das atividades de grupo e que esta atenção não descaracteriza o grupo como tal, pois apesar do todo, as particularidades de cada indivíduo não podem ser desconsideradas.

Foram citados ainda problemas em relação à falta de organização quanto à periodicidade, cronograma e planejamento de ações (Silva et al., 2017; Maia et al., 2018; Costa et al., 2011). Silva (2010) observou que não há planejamento formal para estas atividades na realidade estudada, que as ações são operacionalizadas predominantemente em reunião de equipe, sem planejamento prévio. Silva et al. (2018) concluíram com seu estudo que é de fundamental importância planejar em equipe as ações a serem desenvolvidas.

Outras dificuldades citadas foram em relação à divulgação e falta de encaminhamento formal (Silva, 2010; OnockoCampos et al., 2012; Costa et al., 2011), baixa adesão dos usuários às atividades propostas (Onocko-Campos et al., 2012; Pimentel et al., 2014; Costa et al., 2011) e dois estudos citam problemas relacionados ao compartilhamento de ações entre a equipe (Pimentel et al., 2014; Costa et al., 2013).

Secco (2018) percebeu que a equipe, especialmente as ACS, tem papel importante no despertar o interesse dos usuários em participar das atividades de grupo. Percebe-se que tais profissionais têm conseguido fortalecer o vínculo entre UBS e comunidade favorecendo o acesso aos serviços ofertados e que os usuários participantes do grupo estudado chegaram através de um convite feito por um membro da equipe de saúde. Portanto, é de fundamental importância o papel desempenhado pela equipe na divulgação de tais atividades.

Usuários entrevistados por Fernandes, Souza e Rodrigues (2019) citaram como caminho para chegar aos grupos os próprios profissionais da ESF, e vizinhos, amigos e parentes que já participavam previamente de tais atividades.

Os profissionais entrevistados por Teixeira et al. (2017) também citaram a baixa adesão das usuárias como fator que dificulta a realização de atividades em grupo para gestantes. Brito (2017) realizou estudo com mães de crianças menores de 2 anos e a maioria das entrevistadas afirmou não participar de grupos educativos na UBS e os motivos foram a não disponibilização de tais atividades, falta de tempo, falta de interesse, acesso e horário inadequado.

Em relação à fatores que facilitam ou dificultam a participação em grupo educativo de pré-natal em 4 UBS, embora citando mais fatores facilitadores, algumas das gestantes entrevistadas citaram o horário de realização das atividades educativas em grupo, bem como seu horário de trabalho como fatores que dificultam sua participação em tais ações (Dornelas, 2016). Também Souza e Tyrrell (2016) tiveram relato de enfermeiro entrevistado pontuando o horário de funcionamento da UBS como um fator limitador já que restringe a oferta de grupos em horários distintos.

Em termos de adesão, Almeida et al. (2017) cita momentos de descontração e interação promovidos nos primeiros encontros do grupo como fator favorável à adesão e participação dos usuários às atividades propostas. Cita-se ainda, no referido estudo, que os espaços de grupo possibilitam aperfeiçoamento dos envolvidos tanto pessoal quanto profissionalmente, através da valorização de saberes e da intervenção no processo saúde e doença de maneira criativa.

Matias (2017) percebeu com seu estudo que o que mantém o indivíduo no grupo é a construção da grupalidade, o encontrar-se com outros indivíduos e a construção de si próprio enquanto sujeito. Para os usuários que participam das atividades de grupo observadas no referido estudo, o grupo é considerado um compromisso firmado e não participar de tal atividade é motivo de pesar.

Em estudo realizado por Fernandes, Souza e Rodrigues (2019) foi constatado que grande parte dos usuários que participavam das atividades de grupo estavam desempregados ou eram aposentados, o que, acreditam os autores, pode ter favorecido sua participação em tais ações. Ainda de acordo com os mesmos autores o fato de a unidade de saúde ser próxima à 
moradia dos usuários também favoreceu sua adesão ao grupo. Outros fatores facilitadores citados no mesmo estudo foram horário da atividade compatível com sua rotina e processo de trabalho ajustável.

Constatou-se ainda que o vínculo estabelecido com o profissional, bem como sua relação horizontal com os usuários foi motivo que favoreceu a permanência destes indivíduos no grupo (Fernandes, Souza \& Rodrigues, 2019).

Conforme descrito na Carta de Ottawa (Organização Mundial da Saúde, 1986, p. 2) não cabe apenas ao setor saúde garantir pré-requisitos para a saúde, sendo que "a promoção da saúde demanda uma ação coordenada entre todas as partes envolvidas: governo, setor saúde e outros setores sociais e econômicos, organizações voluntárias e não-governamentais, autoridades locais, indústria e mídia”. Também é descrito que as pessoas devem se envolver enquanto indivíduos, famílias e comunidade neste processo.

Conforme observado por Fernandes, Souza e Rodrigues (2019) em seu estudo a maioria dos usuários procuraram o serviço de saúde devido a presença de alguma patologia e não para promoção e prevenção a saúde, sendo necessário investir mais em ações de educação em saúde baseadas na autonomia e romper o modelo de atenção centrado na doença.

Brito (2016) em estudo que abordou 342 trabalhadores de nível superior da ESF (médicos, cirurgiões dentistas e enfermeiros) percebeu que para os sujeitos entrevistados, estratégias de educação em saúde são utilizadas pela ESF para realizar promoção e prevenção da saúde o que se opõe ao modelo curativista e vai além do tratamento de doenças já instaladas. O autor também constatou que a maioria dos profissionais de nível superior participa de, no mínimo, uma atividade em grupo por semana, sendo que comparando categorias profissionais, médicos participam de um número menor de ações em relação à enfermeiros e cirurgiões dentistas, o que pode ocorrer devido ao modelo biologicista adotado por parte dos trabalhadores médicos, que foca no atendimento individual e curativo.

Em estudo realizado por Souza e Tyrrell (2016) também foi evidenciado que o profissional médico tem maior dificuldade em participar de atividades educativas em grupo devido à grande demanda de atendimentos. Teixeira et al. (2017) também constataram que a demanda elevada gera um excesso de trabalho e acaba por dificultar a realização de atividades de grupo.

Também Maceno e Heidemann (2016) constataram que muitas vezes, atividades de grupo são desativadas devido à baixa adesão dos usuários, a demanda de outras atividades como consultas e visitas domiciliares e falta de profissionais. Concluem ainda que embora existam esforços para a inserção de atividades de promoção da saúde na rotina dos profissionais, predomina o foco nas atividades preventivas e curativas.

Para Batista et al. (2017, p. 269) "o trabalho compartilhado guarda forte relação com os processos educativos e formativos ofertados pelas instituições de ensino, que ainda são pautados no modelo biomédico, fragmentado e especializado". É revelado ainda pelos profissionais entrevistados a pouca motivação para o trabalho e a fragilidade dos vínculos.

Teixeira et al. (2017) sugerem a reflexão de que embora existam dificuldades para a realização de atividades de grupo, os profissionais precisam direcionar seus esforços para a superação de tais dificuldades, utilizando-se de experiências anteriores, sejam positivas ou negativas, para aprender. Salientam ainda, que além de identificar os obstáculos, é necessário que os profissionais se comprometam na elaboração de soluções.

\subsection{O uso de grupos pelo NASF}

Em relação ao trabalho realizado pelo NASF, 4 estudos contemplam profissionais desta equipe em sua amostra, sendo que um deles tratou especificamente sobre o trabalho da equipe NASF na AB (Gonçalves et al., 2015) e um deles sobre a prática do profissional fonoaudiólogo na equipe NASF (Costa et al., 2013). Os outros dois estudos analisaram o todo do trabalho realizado pela equipe de NASF e de ESF (Pimentel et al., 2014; Maia et al., 2018). 
Gonçalves et al. (2015) perceberam que as equipes de NASF e ESF precisam trabalhar juntas, entretanto existem diferenças nos processos de trabalho destas equipes que influenciam esta parceria. Perceberam ainda que o planejamento conjunto entre NASF e ESF foi essencial para ampliar o olhar dos profissionais e o escopo de ações realizadas e também a responsabilização dos membros da equipe sobre as atividades.

Para Almeida et al. (2017) incluir ações do NASF nas Unidades de Saúde é uma medida a ser incentivada. O autor cita que as UBS são espaços privilegiados para desenvolvimento de atividades de promoção da saúde que envolvam exercício físico, já que possibilita a população, muitas vezes suscetível ao sedentarismo e sem acesso a estas atividades, se beneficiar de exercício físico orientado.

Para Brocardo et al. (2018, p. 131) "compreender a dinâmica do funcionamento das equipes NASF na sua interface com as equipes $\mathrm{AB}$ pode ajudar na identificação de ações que contribuam para a operacionalização da atuação compartilhada entre as duas equipes". Facchini, Tomasi e Dilélio (2018) afirmam que qualificar os processos de organização e ter gestão do cuidado realizada por equipe multiprofissional são fatores primordiais para que haja aumento na efetividade da ESF.

A equipe multiprofissional permite uma nova dimensão do trabalho em equipe, onde todos participam do cuidado ao indivíduo, cada um com sua especificidade o que contribui para a melhoria da qualidade das ações de saúde prestadas (Almeida et al., 2017).

Conforme dito em estudo que trata sobre a atuação de fisioterapeutas e fonoaudiólogos na $A B$, os profissionais especialistas devem atuar conforme os princípios da $\mathrm{AB}$ e não apenas de forma individual e reabilitadora. Os autores perceberam que com a atividade de grupo multiprofissional realizada houve redução no número de encaminhamentos médicos para o nível secundário de atenção, confirmando que o trabalho de especialistas com vistas a promoção da saúde na $\mathrm{AB}$ pode auxiliar na resolução de grande parte da demanda trazida pelos usuários. Os autores afirmam ainda que incluir especialistas não médicos na $\mathrm{AB}$ que atuem conforme preconizado para tal nível de atenção amplifica os benefícios, tanto para a comunidade quanto para a equipe e para o SUS (Miolo et al., 2018).

Profissionais participantes de estudo realizado por Batista et al. (2017) relataram maior dificuldade em realizar ações interdisciplinares e coletivas em comparação a atendimentos individuais centrados em um núcleo de saber único, porém, apesar desta dificuldade, acreditam que atividades coletivas e multiprofissionais são mais efetivas.

Matias (2017) percebeu que os grupos, na realidade estudada, são conduzidos por diferentes profissionais sendo dentistas, enfermeiros, educador físico, residente de enfermagem, técnico em saúde bucal e especialmente os ACS. Constatouse que em todos os grupos observados o ACS teve destaque fortalecendo o vínculo entre usuário, profissionais e UBS e mesmo sem a presença de profissionais de nível superior as atividades ocorrem sem intercorrências.

Fernandes, Souza e Rodrigues (2019) perceberam em seu estudo que entrevistou usuários participantes de atividades de grupo desenvolvidas por equipe NASF que houve, conforme relato dos usuários entrevistados, redução nas dores físicas, no uso de medicamentos o que acabou por resultar em melhoria da capacidade funcional e qualidade de vida de tais indivíduos.

Um dos estudos avaliados tratou sobre as temáticas e referencial teórico utilizados em grupos de Educação Alimentar e Nutricional (EAN) realizados na Atenção Primária a Saúde (APS) das cidades de São Paulo (Brasil) e Bogotá (Colômbia). Foi entrevistado um total de 54 nutricionistas, sendo que em São Paulo, todas pertenciam ao NASF. Os grupos realizados em São Paulo eram focados na doença ou em ciclos da vida; já em Bogotá o foco eram três programas pré-estabelecidos (Você é Valioso, Ser Feliz e Agite-se) (Cárdenas, 2013). Cárdenas (2013) constatou que os temas abordados nos grupos avaliados estavam de acordo com as características de tais grupos e que é de fundamental importância que estes temas tenham significado para os participantes objetivando resultados específicos à população que se destina.

Em estudo realizado por Maceno e Heidemann (2016) foi percebido que os temas trabalhados nos grupos são selecionados a partir da realidade da unidade, sendo que profissionais de equipe multiprofissional participam do levantamento 
de temas próprios de suas áreas de atuação. Os entrevistados citaram ainda que se utilizam de roda de conversa para definição de assuntos e buscam temas que não tenham foco na patologia.

Secco (2018, p. 59) percebeu que os profissionais coordenadores da atividade de grupo observada parecem considerar as demandas da comunidade e dos participantes e disponibilizar diferentes alternativas de cuidado, sendo as temáticas abordadas sugestões dos próprios participantes. Para a mesma autora, "quando os usuários se sentem pertencentes, olhados e valorizados pela equipe a adesão ao grupo se torna mais efetiva".

Maceno e Heidemann (2016) descrevem ainda a percepção sobre o desejo de mudança dos profissionais para uso de uma metodologia mais participativa, entretanto, muitos relatam se desestimular devido ao fato de os usuários não participarem ativamente das ações e não se responsabilizarem pela sua própria saúde e além disso, é necessário estimular tais usuários para a mudança.

Para Melo e Castro (2017), em estudo que tratou sobre a inserção do farmacêutico em Unidade Básica de Saúde, destacaram seu importante papel para minimizar problemas relacionados à medicamentos, sendo sua presença, fundamental nas intervenções realizadas. Os autores constataram que nos dois anos estudados foram ofertados 14 grupos de educação em saúde, abrangendo 323 participantes no total, sendo estas ações voltadas ao uso contínuo de medicamentos por hipertensos e diabéticos, cuidados no armazenamento de medicamentos e riscos da automedicação. Além disso, o profissional também participou de grupo multidisciplinar de controle do tabagismo.

\section{Considerações Finais}

Com o presente estudo foi possível perceber que o trabalho em grupos na atenção básica traz inúmeros benefícios, dentre eles o fortalecimento de vínculo entre equipe de saúde e usuários, a troca de experiências entre equipe de saúde e usuários e, também entre os próprios usuários, o fortalecimento de laços entre membros de uma mesma comunidade, um olhar ampliado sobre a saúde do indivíduo participante da atividade, especialmente quando tal atividade é conduzida por equipe multiprofissional

Porém, apesar de tantos benefícios, muitas dificuldades ainda permanecem, pôde ser observado neste estudo dificuldades referentes à estrutura física inadequada, resistência por parte da gestão e de alguns profissionais no desenvolvimento de atividades de grupo, sobrecarga de trabalho/demanda elevada que dificulta ou impossibilita a participação de alguns profissionais nas atividades, baixa adesão dos usuários às atividades propostas.

É preciso que os profissionais que atuam na $\mathrm{AB}$ estejam preparados para lidar com tais percalços. Acredita-se que este preparo deve começar em seu processo de formação acadêmica e continuar através de atividades de formação e educação continuada proporcionadas aos trabalhadores.

Em se tratando do trabalho em equipe multiprofissional, foi percebido que onde ocorre esta troca de saberes bons resultados são colhidos, para tanto, é necessário que haja planejamento conjunto, partindo das necessidades da população de cada território.

Pode-se inferir que as equipes de NASF tem muito a contribuir para a consolidação das atividades educativas em grupo realizadas na $\mathrm{AB}$ como ferramenta de trabalho, já que se trata de equipe multiprofissional cujo modelo de trabalho favorece a realização de tais ações. Infelizmente, o momento atual é de incertezas em relação a manutenção de tais equipes e cabe refletir sobre suas contribuições desde que foram implantadas.

\section{Referências}

Almeida, A. A. S., Silva, S. C., Araújo, W. T. C., Vasconcelos, S. M. L., Mélo, M. T. S. (2017). Alimentação saudável na perspectiva multiprofissional: a experiência do projeto "Saúde no Prato" desenvolvido na Atenção Básica. Revista Brasileira de Educação e Saúde, 7(4), 109-116. 
http://www2.ebserh.gov.br/documents/14003/3163298/ARTIGO+SAUDE+NO+PRATO+-+04062018.pdf/bab1be1b-f812-4243-8c43-e9b9a8604c2f. http://dx.doi.org/10.18378/ rebes.v7i4.5180

Batista, C. B., Machado, R. M. C., Maciel, F. J., Morais, M. C. N., Paula, P. P. (2017). Trabalho do Núcleo de Apoio à Saúde da Família em um município de Minas Gerais. Gerais: Revista Interinstitucional de Psicologia, 10(2), 264-274. http://pepsic.bvsalud.org/pdf/gerais/v10n2/11.pdf

Bertoncello, P. (2018). Estratégia de grupo na Atenção Básica: o caso de uma unidade de saúde de Florianópolis (SC). (Residência Multiprofissional em Saúde da Família). Universidade Federal de Santa Catarina, Centro de Ciências da Saúde, Florianópolis, SC, Brasil. https://repositorio.ufsc.br/bitstream/handle/123456789/185940/TCR\%20-\%20PAOLA\%20BERT ONCELLO.pdf?sequence=1\&isAllowed=y

Brito, G. E. G. (2016). O processo de trabalho na Estratégia Saúde da Família: um estudo de caso. (Tese de doutorado). Fundação Oswaldo Cruz, Centro de Pesquisas Aggeu Magalhães, Recife, PE, Brasil. Recuperado de https://www.arca.fiocruz.br/bitstream/icict/15960/2/2016brito-geg.pdf

Brito, P. B. (2017). Roteiro para implementação de grupo educativo de promoção da alimentação infantil saudável em Unidades Básicas de Saúde. (Dissertação de mestrado). Universidade de São Paulo, Escola de Enfermagem, São Paulo, SP, Brasil. https://teses.usp.br/teses/disponiveis/7/7144/tde05112018-121552/publico/Pollyana_Boaventura_corrigida.pdf

Brocardo, D., Andrade, C. L. T., Fausto, M. C. R., Lima, S. M. L. (2018). Núcleo de Apoio à Saúde da Família (Nasf): panorama nacional a partir de dados do PMAQ. Saúde Debate, 42(1), 130-144. https://www.scielo.br/pdf/sdeb/v42nspe1/0103-1104-sdeb-42-spe01-0130.pdf. 10.1590/0103-11042018S109

Cárdenas, A. P. (2013). Educação Alimentar e Nutricional em nível de Atenção Primária à Saúde em São Paulo e Bogotá: cenário e temáticas. (Dissertação de mestrado). Universidade de São Paulo, Faculdade de Saúde Pública, São Paulo, SP, Brasil. https://teses.usp.br/teses/disponiveis/6/6138/tde-17042013110402/publico/AlexandraCardenasPortugues.pdf

Cooper, H. M. (1984). The integrative research review: a systematic approach. Beverly Hills: Sage.

Costa, L. S., Alcântara, L. M., Alves, R. S., Lopes, A. M. C., Silva, A. O., Sá, L.D. (2013). A prática do fonoaudiólogo nos Núcleos de Apoio à Saúde da Família em municípios paraibanos. CoDAS, 25(4), 381-387. https://www.scielo.br/pdf/codas/v25n4/14.pdf

Costa, G. D., Cotta, R. M. M., Reis, J. R., Ferreira, M. L. S. M., Reis, R. S., Franceschini, S. C. C. (2011). Avaliação da atenção à saúde da criança no contexto da Saúde da Família no município de Teixeiras, Minas Gerais (MG, Brasil). Ciência e Saúde Coletiva, 16(7), 3229-3240. https://www.scielo.br/pdf/csc/v16n7/22.pdf

Costa, J. M. B. S., Silva, M. R. F., Carvalho, E. F. Avaliação da implantação da atenção à hipertensão arterial pelas equipes de Saúde da Família do município do Recife (PE, Brasil). (2011). Ciência e Saúde Coletiva, 16(2), 623-633. https://www.scielo.br/pdf/csc/v16n2/v16n2a26.pdf

Dantas, L. R. O., Barbosa, E. P., Araújo, I. C. S., Dantas, C. R., Pereira, W. L. Promoção do uso de plantas medicinais em grupo na Atenção Básica - relato de experiência. (2019). Revista Brasileira de Educação e Saúde, 9(3), 66-69. https://www.gvaa.com.br/revista/index.php/REBES/article/view/6520/6351. https://doi.org/10.18378/rebes.v9i3.6520

Diógenes, J. M. P., Moreira, A. E. M. M., Ellery, A. E. L., Ribeiro, M. T. A. M. Psicologia comunitária e Atenção Básica em Saúde: contribuições para abordagem com grupos. (2016). Sanare, 15(1), 32-38. Recuperado de https://sanare.emnuvens.com.br/sanare/article/view/925

Domingues, F., Pinto, F. S., Pereira, V. M. Grupo de gestantes na Atenção Básica: espaço para construção do conhecimento e experiências na gestação. (2018). Revista da Faculdade de Ciências Médicas de Sorocaba, 20(3), 150-154. https://revistas.pucsp.br/index.php/RFCMS/article/view/30648/pdf. doi: $10.23925 / 1984-4840.2018 v 20 i 3 a 6$

Dornelas, R. F. (2016). Participação de gestantes em grupos educativos do pré-natal na Atenção Básica. (Dissertação de mestrado). Universidade Federal de Goiás, Núcleo de Estudos em Saúde Coletiva, Programa de Pós-Graduação em Saúde Coletiva, Goiânia, GO, Brasil. https://repositorio.bc.ufg.br/tede/bitstream/tede/7155/5/Disserta\%c3\%a7\%c3\%a3o\%20-\%20Rodrigo\%20Faria\%20Dornelas\%20-\%202016.pdf

Facchini, L. A., Tomasi, E., Dilélio, A. S. Qualidade da Atenção Primária à Saúde no Brasil: avanços, desafios e perspectivas. (2018). Saúde Debate, 42(1), 208-223. Recuperado de https://www.scielo.br/pdf/sdeb/v42nspe1/0103-1104-sdeb-42-spe01-0208.pdf. doi: 10.1590/0103-11042018S114

Fernandes, E. T. P., Souza, M. N. L., Rodrigues, S. M. Práticas de grupo do Núcleo de Apoio à Saúde da Família: perspectiva do usuário. (2019). Physis: Revista de Saúde Coletiva, 29(1), 1-18. https://www.scielo.br/pdf/physis/v29n1/0103-7331-physis-29-01-e290115.pdf. doi: http://dx.doi.org/10.1590/S010373312019290115

Friedrich, T. L., Petermann, X. B., Miolo, S. B., Pivetta, H. M. F. Motivações para práticas coletivas na Atenção Básica: percepção de usuários e profissionais. (2018). Interface comunicação saúde educação, 22(65), 373-385. https://www.scielo.br/pdf/icse/v22n65/1807-5762-icse-1807-576220160833.pdf. doi: $10.1590 / 1807-57622016.0833$

Gomes, A. F. D. S. (2017). Limites e possibilidades para ações de promoção da saúde da pessoa idosa na Estratégia de Saúde da Família: um estudo de caso. (Dissertação de mestrado). Universidade do Estado do Rio de Janeiro, Centro Biomédico, Faculdade de Enfermagem, Rio de Janeiro, RJ, Brasil. http://www.bdtd.uerj.br/tde_busca/arquivo.php?codArquivo=12912

Gonçalves, R. M. A., Lancman, S., Sznelwar, L. I., Cordone, N. G., Barros, J. O. Estudo do trabalho em Núcleos de Apoio à Saúde da Família (NASF), São Paulo, Brasil. (2015). Revista Brasileira de Saúde Ocupacional, 40(131), 59-74. https://www.scielo.br/pdf/rbso/v40n131/0303-7657-rbso-40-131-59.pdf. http://dx.doi.org/10.1590/0303-7657000078013

Luz, C. A. S., Libório, R., Palombo, C. N. T, Silva, J. C. Núcleo de Apoio à Saúde da Família para gestante num grupo educativo: relato de experiência. (2019). Cuid Enferm, 13(2), 199-203. http://www.webfipa.net/facfipa/ner/sumarios/cuidarte/2019v2/199.pdf.

Maceno, P. R., Heidemann, I. T. S. B. Desvelando as ações dos enfermeiros nos grupos da Atenção Primária à Saúde. (2016). Texto e Contexto Enfermagem, 25(4), 1-9. https://www.scielo.br/pdf/tce/v25n4/pt_0104-0707-tce-25-04-2140015.pdf. http://dx.doi.org/10.1590/0104-07072016002140015 
Maffacciolli, R., Lopes, M. J. M. (2011). Os grupos na atenção básica de saúde de Porto Alegre: usos e modos de intervenção terapêutica. Ciência e Saúde Coletiva, 16(Supl. 1), 973-982. https://www.scielo.br/pdf/csc/v16s1/a29v16s1.pdf

Maia, J. D. S., Silva, A. B., Melo, R. H. V., Rodrigues, M. P., Júnior, A. M. (2018). A educação em saúde para usuários hipertensos: percepções de profissionais da Estratégia Saúde da Família. Ciência Plural, 4(1), 81-97. https://periodicos.ufrn.br/rcp/article/view/13634/9822

Matias, O. S. (2017). Grupos de educação em saúde nas Unidades Básicas de Saúde: concepções de quem faz. (Dissertação de mestrado). Universidade Federal Fluminense, Programa Acadêmico em Ciências do Cuidado em Saúde, Niterói, RJ, Brasil. https://app.uff.br/riuff/bitstream/1/3998/1/Priscila\%20da\%20Silva\%20Matias.pdf

Medeiros, E. A., Santos, V. E. P., Silva, M. D. S., Santos, S. S., Matos, K. K. C., Cruz, N. M. (2012). O cuidado na visão de portadores de hipertensão arterial. Revista de pesquisa: cuidado é fundamental online, 4(2), 2306-2311. https://www.redalyc.org/pdf/5057/505750893024.pdf

Melo, D. O., Castro, L. L. C. A contribuição do farmacêutico para a promoção do acesso e uso racional de medicamentos essenciais no SUS. (2017). Ciência e Saúde Coletiva, 22(1), 235-244. https://www.scielo.br/pdf/csc/v22n1/1413-8123-csc-22-01-0235.pdf. 10.1590/1413-81232017221.16202015

Melo, E. A., Mendonça, M. H. M., Oliveira, J. R., Andrade, G. C. L. (2018). Mudanças na Política Nacional de Atenção Básica: entre retrocessos e desafios. Saúde Debate, 42(1), 38-51. https://www.scielo.br/pdf/sdeb/v42nspe1/0103-1104-sdeb-42-spe01-0038.pdf. 10.1590/0103-11042018S103

Melo, R. H. V., Melo, M. L., Vilar, R. L. A. (2018). Análise de redes sociais: a reciprocidade entre usuários e profissionais na Estratégia Saúde da Família. Ciência Plural, 4(1) 22-35. https://periodicos.ufrn.br/rcp/article/view/13626/9818

Ministério da Saúde. (2014). Cadernos de Atenção Básica, $n^{\circ}$ 39. Núcleo de Apoio à Saúde da Família - Volume 1: Ferramentas para a gestão e para o trabalho cotidiano. Brasília: Autor. https://bvsms.saude.gov.br/bvs/publicacoes/nucleo_apoio_saude_familia_cab39.pdf

Ministério da Saúde. (2017). Portaria $n^{o}$ 2.436, de 21 de setembro de 2017. Autor. https://bvsms.saude.gov.br/bvs/saudelegis/gm/2 017/prt2436_22_09_2017.html

Miolo, S. B., Schiavo, L. P., Petermann, X. B., Fedosse, E. (2018). Contribuições das especialidades não-médicas na Atenção Básica: cuidado transdisciplinar em grupos de saúde. Saúde (Santa Maria), 44(2), 1-10. https://periodicos.ufsm.br/revistasaude/article/view/30624/pdf. 10.5902/2236583430624

Onocko-Campos, R. T., Campos, G. W. S., Ferrer, A. L., Corrêa, C. R. S., Madureira, P. R., Gama, C. A. P., \& Nascimento, R. (2012). Avaliação de estratégias inovadoras na organização da Atenção Primária à Saúde. Revista de Saúde Pública, 46(1), 43-50. https://www.scielo.br/pdf/rsp/v46n1/2502.pdf

Organização Mundial de Saúde. (1986). Carta de Ottawa - Primeira Conferência Internacional sobre Promoção da Saúde. Ottawa: Autor. http://bvsms.saude.gov.br/bvs/publicacoes/carta_ottawa.pdf

Pimentel, V. R. M., Sousa, M. F., Hamann, E. M., Mendonça, A. V. M. Alimentação e nutrição na Estratégia Saúde da Família em cinco municípios brasileiros. (2014). Ciência e Saúde Coletiva, 19(1), 49-57. https://www.scielo.br/pdf/csc/v19n1/1413-8123-csc-19-01-00049.pdf. doi: 10.1590/141381232014191.1901

Portaria $n^{\circ}$ 2.436, de 21 de setembro de 2017. Aprova a Política Nacional de Atenção Básica, estabelecendo a revisão de diretrizes para a organização da Atenção Básica, no âmbito do Sistema Único de Saúde (SUS). http://bvsms.saude.gov.br/bvs/saudelegis/gm/2017/prt2436_22_09_2017.html

Rocha, I. A., Sá, A. N. P., Braga, L. A. V., Ferreira Filha, M. O., Dias, M. D. (2013). Terapia comunitária integrativa: situações de sofrimento emocional e estratégias de enfrentamento apresentadas por usuários. Revista Gaúcha de Enfermagem, 34(2), 155-162. https://www.scielo.br/pdf/rgenf/v34n3/a20v34n3.pdf

Santos, B. Z. B. (2018). Avaliação da vivência de participantes em dois modelos de grupos educativos em alimentação e nutrição. (Dissertação de mestrado). Universidade de São Paulo, Faculdade de Saúde Pública, São Paulo, SP, Brasil. Recuperado de https://teses.usp.br/teses/disponiveis/6/6138/tde-03102018085518/publico/BrunaZillesgBorgesdosSantos_MTR_ORIGINAL.pdf

Secco, A. C. (2018). Os grupos de promoção de saúde como dispositivos de cuidado na Atenção Básica. (Dissertação de mestrado). Universidade Federal de Santa Maria, Centro de Ciências Sociais e Humanas, Programa de Pós-Graduação em Psicologia. https://repositorio.ufsm.br/bitstream/han dle/1/15308/DIS_PPGPSICOLOGIA_2018_SECCO_ANA.pdf?sequence=1\&isAllowed=y

Silva, J. L. (2010). A prática educativa como expressão da prática profissional no contexto da Equipe de Saúde da Família no município do Rio de Janeiro. (Dissertação de mestrado). Universidade do Estado do Rio de Janeiro, Centro Biomédico, Faculdade de Enfermagem. http://www.bdtd.uerj.br/tde_busca/arquivo.php?codArquivo=2618

Silva, A. B., Rodrigues, M. P., Oliveira, A. P., Melo, R. H. V. (2017). Prevenção do câncer cervicouterino: uma ação realizada pelos enfermeiros da Estratégia Saúde da Família? Ciência Plural, 3(2), 99-114. https://periodicos.ufrn.br/rcp/article/view/12926/8993

Silva, S. T. R. C., Melo, S. N., Torres, B. R. S., Assis, R. R. T., Bomfim, A. M. A., Lucena, A. R. S., \& Lucena, M. S. Abordagem dinâmica das complicações do Diabetes Mellitus e da hipertensão arterial quando negligenciadas: um relato de experiência. Ciência Plural, 4(1), 36-43. https://periodicos.ufrn.br/rcp/article/view/13757/9819

Souza, M. D., Tyrrell, M. A. R. Direitos sexuais e reprodutivos na Atenção Básica:educação em saúde grupal sob a ótica da enfermeira. (2016). Revista Iberoamericana de Educación e Investigación en Enfermería, 6(3), 49-58. https://www.enfermeria21.com/revistas/aladefe/articulo/213/direitos-sexuais-ereprodutivos-na-atencao-basica-educacao-em-saude-grupal-sob-a-otica-da-enfermeira/

Teixeira, J. A., Soares, M. C., Escobal, A. P. L., Gonçalves, K. D., Matos, G. C., Silva, B. M. P., Rocha, K. S. (2017). Percepção dos profissionais de saúde da Atenção Básica sobre os grupos de gestantes. Saúde (Santa Maria), 43(1), 94-103. https://periodicos.ufsm.br/revistasaude/article/view/22413/pdf 